\title{
Bazı maki türlerinin kimyasal içeriği ve fenolik ekstraktifleri üzerine araştırmalar
}

\author{
Samim Yaşar ${ }^{\text {a, }}$, Faruk Demir $^{\mathrm{a}}$, Yasin Karatepe ${ }^{\mathrm{b}}$
}

Özet: Maki bitkileri olan Styrax officinalis, Fontanesia philliraeoides, Myrtus communis, Paliurus spina-christi ve Pistacia terebinthus türlerini ele alan bu çalışmada, söz konusu türlerin kimyasal bileşimleri ve fenolik ekstraktifleri belirlenmiş, antioksidan üretiminde ve orman endüstrisinde hammadde olarak kullanılabilirlikleri değerlendirilmiștir. Bitkilere ait örneklerde şu değerler elde edilmiştir: Holoselüloz \%72.20-74.64, selüloz \%50.93-53.48, $\alpha$-selüloz \%41.16-43.50, lignin \%22.22-24.46, kül \%1.72-2.63, etanol siklohekzan çözünürlüğü \%2.33-3.15, soğuk su çözünürlüğü \%10.21-15.27, sicak su çözünürlüğü \%10.4115.92 ve \%1 NaOH çözünürlüğü \%26.64-30.09 aralığında sıralanmıştır. HPLC analizleri klorojenik asitin (0.15 mg/g) Styrax officinalis'de, gallik asitin ( 0.59 ve $0.91 \mathrm{mg} / \mathrm{g})$ Myrtus communis ve Pistacia terebinthus'de, kateşinin ( $0.08 \mathrm{mg} / \mathrm{g})$ Fontanesia philliraeoides'de ve epikateşinin $(0.85 \mathrm{mg} / \mathrm{g})$ Paliurus spina-christi' de en yüksek değere sahip fenolik ekstraktif madde olduğunu göstermiştir. Sonuçlar, elde edilen değerler doğrultusunda adı geçen maki türlerinin orman endüstrisine alternatif hammadde olabilecek ve ticari antioksidan üretiminde kullanılabilecek düzeyde olduğunu ortaya koymuştur.

Anahtar kelimeler: Maki türleri, Kimyasal kompozisyon, Fenolik ekstraktifler

\section{Studies on chemical composition and phenolic extractives of some maquis species}

\begin{abstract}
In this study which focused on Styrax officinalis, Fontanesia philliraeoides, Myrtus communis, Paliurus spina-christi and Pistacia terebinthus, the chemical composition and the phenolic extractives in the maquis plants were determined. Practicability of mentioned species as raw material in the forest industry and in the production of antioxidant was examined. In the samples, the following values were determined: Holocellulose $72.20-74.64 \%$, cellulose $50.93-53.48 \%$, $\alpha$-cellulose 41.16 $43.50 \%$, lignin $22.22-24.46 \%$, ash $1.72-2.63 \%$, ethanol cyclohexane solubility $2.33-3.15 \%$, cold water solubility $10.21-15.27 \%$, hot water solubility $10.41-15.92 \%$ and $1 \% \mathrm{NaOH}$ solubility between $26.64-30.09 \%$. HPLC analyses indicated that chlorogenic acid $(0.15 \mathrm{mg} / \mathrm{g})$ was the major phenolic extractive in the Styrax officinalis, gallic acid $(0.59$ and $0.91 \mathrm{mg} / \mathrm{g})$ in the Myrtus communis and Pistacia terebinthus, catechin $(0.08 \mathrm{mg} / \mathrm{g})$ in the Fontanesia philliraeoides and epicatechin $(0.85 \mathrm{mg} / \mathrm{g})$ in the Paliurus spina-christi. The results showed that the obtained values from mentioned maquis species were found to be at a sufficient level for raw material in the forest industry and in the production of commercial antioxidant.

Keywords: Maquis species, Chemical composition, Phenolic extractives
\end{abstract}

\section{Giriș}

Dünyada nüfusun hıla artması ve buna paralel olarak sanayileşme ile birlikte son yıllarda orman ürünlerine olan talep giderek artmıştır. Dünya nüfusunun yıllık artış1 yaklaşık olarak 90 milyona ulaşmıştır. Odun orman endüstrisinde kullanılan hammaddelerin başında gelmektedir. Dünyada kurutulmamış odun kullanımı yılda 3.5 milyar ton düzeyindedir ve kişi başına düşen odun miktarı 0.7 ton civarında olmaktadır. $\mathrm{Bu}$ tüketimin gün geçtikçe artacağı öngörülmektedir. Orman kaynaklarının azalması gün geçtikçe artan talebin karşılanabilmesi için hammadde kaynaklarının planlı ve verimli bir şekilde kullanılmasının gerekliliğini gözler önüne sermiştir. Ayrıca, odun hammaddesinin günden güne çok değişik alanlarda kullanımı artmaktadır. Dolayıs syla odun hammaddesine olan talep ve mevcut arz arasındaki dengesizliğ in kaçınılmaz olacağı gözönündedir. Bu nedenle, odun esas lı lifler yerine tarımsal ve diğer kaynaklı alternatif liflerin kullanılması, kullanılan hammaddenin geri dönüşümü, daha etkin teknolojiler, yeni ve daha kaliteli ürünlerin geliştirilmesi gelecekte odun arz ve talep dengesinin düzenlenmesinde önemli bir rol oynayacaktır (Cooper ve Balatinecz, 1999). Küresel ısınmanın etkilerinin hissedilmeye başlandığ 1 günümüzde ormanların değeri ve önemi bir kez daha net olarak ortaya çıkmış, bu doğrultuda gerekli önlemlerin alınması ve gerekli çalışmaların yapılması kaçınılmaz hale gelmiştir (Öner ve Aslan, 2002).

Bitki ve baharatları doğal antioksidan kaynakları olarak araştıran çalışmaların sayısı gün geçtikçe artış göstermektedir. $\mathrm{Bu}$ hususta yaplan incelemeler bitkisel materyallerin güçlü antioksidan ve antimikrobiyal aktiviteye sahip çok sayıda kimyasal madde içerdiğini göstermiştir. Bilindiği üzere, doğal kaynaklardan elde edilen antioksidanlar gıda ve ilaç endüstrisinde sıkça kullanılmaktadır. Fenolik maddelerin doğal antioksidan $\llbracket$ a Süleyman Demirel Üniversitesi, Orman Fakültesi, Orman Endüstri Mühendisliği Bölümü, 32260 Isparta, Türkiye

${ }^{\text {b }}$ Süleyman Demirel Üniversitesi, Orman Fakültesi, Orman Mühendisliği Bölümü, 32260 Isparta, Türkiye

@ * Corresponding author (İletişim yazarı): samimyasar@sdu.edu.tr

$\checkmark$ Received (Geliş tarihi): 28.01.2016, Accepted(Kabul tarihi): 25.02.2016
Citation (Atıf): Yaşar, S., Demir, F., Karatepe, Y., 2016. Bazı maki türlerinin kimyasal içeriği ve fenolik ekstraktifleri üzerine araştırmalar. Turkish Journal of Forestry, 17(2): 187-193. DOI: $\underline{10.18182 / \mathrm{tjf} .22143}$ 
olmakla beraber kalp hastalıklarında ve kanser tedavisinde de önleyici rol oynadıklan ortaya konulmuştur (Faydaoğlu ve Sürücüoğlu, 2013; Willför vd., 2003; Dönmez vd., 2016).

$\mathrm{Bu}$ çalışmada, hammadde olabilme doğrultusunda iğne yapraklı ve yapraklı ağaçlara alternatif olarak kullanılabilecek veya birlikte değerlendirilebilecek bitkisel kaynak niteliği taşıyan ve maki vejetas yonu içeris inde geniş bir yayılış alanına sahip olan Styrax officinalis (Tespih), Pistacia terebinthus (Menengiç), Myrtus communis (Mersin), Fontanesia phillreaoides (Çılbırtı) ve Paliurus spina-christi (Karaçalı) türleri kimyasal içerik ile fenolik ekstraktif madde çeşitliliği ve miktarları yönünden incelenmiştir.

\section{Materyal ve yöntem}

\subsection{Materyal}

Çalışmada kullanılacak örnekler, 2010 yılı Eylül ayında Aşağıgökdere'nin (Isparta) doğusunda yer alan bölgeden temin edilmiştir. Tespih, menengiç, mersin, çılbırtı ve karaçalı olmak üzere beş maki bitkisinden alınan dal ve gövde örnekleri materyal olarak kullanılmıştır. Her bir tür için beş farklı bireyden örnekler elde edilmiştir. Dal örnekleri bitkinin en yüksek noktasından aşağıya doğru tepe tacının 1/3'lük kısmının alt sınırından dört farklı yönde alınmıştır. Gövde örnekleri ise gövdenin orta kısımlarından alınmıştır.

Temin edilen dal ve gövde örnekleri kabukları soyulduktan sonra yongalanmış ve hava kurusu hale getirilerek karıştırılmıştır. Öğütme işlemi Retsch SK1 değirmeni ile yapılmış ve örnekler 40-100 mesh'lik eleklerden geçirilmiştir.

\subsection{Yöntem}

Etanol-siklohekzan çözünürlüğü için, her bir türe ait materyal ekstraksiyon balonuna alınmış ve soxhlet cihazında öncelikle etanol siklohekzan (1:2) karışımı ile 6 saat ve devamında etanol ile eks traksiyona tabi tutulmuş tur. Holoselüloz tayini Wise ve Karl (1962)'a, selüloz tayini Kurschner ve Hoffer (1969)'e göre yapılmıştır. $\alpha$-selüloz tayini TAPPI T 203 os-71, Lignin tayini TAPPI T 222 om88, Kül tayini TAPPI T 211 om-85, Suda çözünürlük TAPPI T 207 om-88 ve \%1'lik NaOH çözünürlügü TAPPI T 212 om-88 yöntemleri kullanılarak gerçekleş tirilmiş tir.
Fenolik ekstraktif madde analizi örneklerin soxhlet cihazında 6 saat süreyle metanol ekstraksiyonu sonucu elde edilen ekstraktlarda SHIMADZU sistem HPLC cihazı ve DAD dedektör ile Caponio vd., (1999)'ne ait yöntem modifiye edilerek şu şekilde gerçekleş tirilmiş tir: Enjeksiyon hacmi $20 \mu \mathrm{L}$ şeklinde ayarlanmıştır. Mobil faz olarak A:\% 3 asetik asit ile B: metanol kullanılmış (Çizelge 1) ve akış hızı dakikada $0.8 \mathrm{~mL}$ olacak şekilde düzenlenmiştir. Kromatografik ayırma Agilent Eclipse XDB-C18 kolonu (250x4.6 mm; id $5 \mu \mathrm{m})$ ile $30{ }^{\circ} \mathrm{C}$ 'de yerine getirilmiştir.

\section{Bulgular ve tartışma}

Örneklerin kimyasal bileşimi ve çözünürlük değerleri Çizelge 2'de verilmiştir. Holos elüloz miktarları \%72.2074.64, selüloz miktarları \%50.93-53.48, $\alpha$-selüloz miktarları $\% 41.16-43.50$, lignin miktarları \%22.22-24.46, kül miktarları \%1.72-2.63, etanol siklohekzan çözünürlüğü \%2.33-3.15, soğuk su çözünürlüğü \%10.21-15.27, sıcak su çözünürlüğü \%10.41-15.92 ve \%1 NaOH çözünürlüğü \%26.64-30.09 aralığında tespit edilmiştir.

Çalışma örneklerine ait yüzdes el değerlerden ayrı ayrı 3 elemanlı gruplar halinde veri kütükleri oluşturulmuş ve devamında yüzdesel değerlerin $\operatorname{Arcsin}^{1 / 2}$ dönüşümleri yapılmıştır. İlk olarak aritmetik ortalamalar Basit varyans analizi (Anova Testi) ile kontrol edilmiştir. Anova testi sonucundais tatiksel açıdan farklılığın oluştuğu durumlarda farklı grupların tespit edilebilmesi için Duncan testi uygulanmıştır. $\mathrm{P}<0.001$ düzeyinde tespih ve çılbırtı ile mersin ve menengiçte holoselülozgrupları, tespih ve çılbırtı ile mers in ve menengiçte selüloz grupları, tespih ve çılbırtı ile mers in ve menengiçte lignin grupları, tespih ve çılbırtı ile karaçalı ve menengiçte kül grupları, tespih ve karaçalı ile çılbırtı ve mers in yanıs ıra karaçalı ve menengiçte etanol siklohekzan çözünürlügü grupları, mersin ve menengiçte soğuk su çözünürlüğü grupları, mersin ve karaçalıda sıcak su çözünürlüğü grupları aritmetik ortalamalar bakımından benzer bulunmuş, ancak $\alpha$-selüloz ve $\% 1 \mathrm{NaOH}$ çözünürlüğü grupları tüm örneklerde farklllık göstermiştir (Çizelge 2).

Çizelge 1. HPLC gradient programı

\begin{tabular}{crrrrrrrrrrrr}
\hline Dakika & 0.1 & 20 & 28 & 35 & 50 & 60 & 62 & 70 & 73 & 75 & 80 & 81 \\
\hline$\% \mathrm{~A}$ & 93 & 72 & 75 & 70 & 70 & 67 & 58 & 50 & 30 & 20 & 0 & 93 \\
$\% \mathrm{~B}$ & 7 & 28 & 25 & 30 & 30 & 33 & 42 & 50 & 70 & 80 & 100 & 7 \\
\hline$\% \mathrm{~A}: \%$ & Asetik asit, \%B: Metanol & & & & & &
\end{tabular}

Çizelge 2. Örneklerin kimyasal bileşimi ve çözünürlük değerleri (\%)

\begin{tabular}{|c|c|c|c|c|c|}
\hline & Tespih & Çilbırt1 ${ }^{2}$ & Mersin $^{3}$ & Karaçalı $^{4}$ & Menengiç \\
\hline Holoselüloz miktarı & $73.32^{a}$ & $73.55^{a}$ & $72.64^{\circ}$ & $74.64^{c}$ & $72.20^{\circ}$ \\
\hline Selüloz miktarı & $52.39^{\mathrm{a}}$ & $52.17^{\mathrm{a}}$ & $50.93^{\mathrm{b}}$ & $53.48^{\mathrm{c}}$ & $51.31^{\mathrm{b}}$ \\
\hline$\alpha$-selüloz miktarı & $43.00^{\mathrm{a}}$ & $42.23^{\mathrm{b}}$ & $41.16^{\mathrm{c}}$ & $43.50^{\mathrm{d}}$ & $41.75^{\mathrm{e}}$ \\
\hline Lignin miktarı & $23.22^{\mathrm{a}}$ & $23.13^{\mathrm{a}}$ & $24.11^{\mathrm{b}}$ & $22.22^{\mathrm{c}}$ & $24.46^{\mathrm{b}}$ \\
\hline Kül miktarı & $1.72^{\mathrm{a}}$ & $1.76^{\mathrm{a}}$ & $2.10^{\mathrm{b}}$ & $2.55^{\mathrm{c}}$ & $2.63^{\mathrm{c}}$ \\
\hline Etanol siklohekzan çözünürlüğü & $3.15^{\mathrm{a}}$ & $2.39^{\mathrm{b}}$ & $2.33^{\mathrm{b}}$ & $2.91^{\mathrm{ac}}$ & $2.73^{\mathrm{c}}$ \\
\hline Soğuk su çözünürlüğü & $15.27^{\mathrm{a}}$ & $10.45^{\mathrm{b}}$ & $10.23^{c}$ & $12.04^{\mathrm{d}}$ & $10.21^{\mathrm{c}}$ \\
\hline Sıcak su çözünürlüğü & $15.92^{\mathrm{a}}$ & $12.27^{\mathrm{b}}$ & $12.85^{\mathrm{c}}$ & $12.63^{\mathrm{c}}$ & $10.41^{\mathrm{d}}$ \\
\hline \%1 NaOH çözünürlüğü & $30.09^{\mathrm{a}}$ & $28.11^{\mathrm{b}}$ & $28.75^{\mathrm{c}}$ & $28.45^{\mathrm{d}}$ & $26.64^{\mathrm{e}}$ \\
\hline
\end{tabular}

1: Styrax officinalis, 2: Fontanesia phillreaoides, 3: Myrtus communis, 4: Paliurus spina-christi, 5: Pistacia terebinthus, a-e: Duncan testi homojen gruplar1 
Kılıç vd. (2010) tarafindan sarıçam (Pinus sylvestris) odununda holoselüloz \%71.4, $\alpha$-selüloz $\% 48.6$, lignin $\% 27.6$, kül \%0.3, alkol benzen çözünürlüğü \%2.8, sıak su çözünürlüğü \%3.1, soğuk su çözünürlüğü \%1.7 ve \%1 $\mathrm{NaOH}$ çözünürlüğü \%12.9, karaçam (Pinus nigra) odununda holoselüloz $\% 71.5, \alpha$-selüloz $\% 50.4$, lignin $\% 26.7$, kül \%0.2, alkol benzen çözünürlüğü \%3.2, sıak su çözünürlüğü \%4.2, soğuk su çözünürlüğü \%2.1 ve \%1 $\mathrm{NaOH}$ çözünürlüğü \%12.8, kızılçam (Pinus brutia) odununda ise holoselüloz $\% 72.6, \alpha$-selüloz $\% 46.5$, lignin \%27.3, kül \%0.4, alkol benzen çözünürlüğü \%2.3, sıak su çözünürlüğü \%3.3, soğuk su çözünürlüğü \%2.6 ve \%1 $\mathrm{NaOH}$ çözünürlüğü \%12.6 olarak belirlenmiştir. Selüloz miktarı sarıçam odununda \%54.8 (Usta, 1989), karaçam odununda \%51.9 (Kırc1 vd., 2002) ve kızılçam odununda \%54.1 (Kırc1, 1991) şeklinde rapor edilmiştir.

Gülsoy (2003) tarafindan yapılan çalışmada saplı meşe (Quercus robur) odununda holoselüloz \%68, selüloz \%42.5, lignin $\% 24.5$, kül \%0.63, alkol benzen çözünürlüğü \%6.6, sıcak su çözünürlüğü \% 10 , soğuk su çözünürlüğü \%6.5 ve $\% 1 \mathrm{NaOH}$ çözünürlüğü \%22.4 olarak belirlenmiştir. Aynı çalışmada, ova akçaağacı (Acer campestre) odununda holoselüloz $\% 75.2$, selüloz $\% 50.9$, lignin $\% 23.8$, kül \%0.7, alkol benzen çözünürlüğü \%4.1, sıcak su çözünürlüğü \%5.7, soğuk su çözünürlüğü \%3.4 ve \%1 NaOH çözünürlüğü $\% 16.7$ ve adi gürgen (Carpinus betulus) odununda holoselüloz \%79.6, selüloz \%49.6, lignin \%18.9, kül \%0.4, alkol benzen çözünürlüğü \% 4.9, sicak su çözünürlüğü \%6.3, soğuk su çözünürlüğü \%4.6 ve \%1 NaOH çözünürlüğü \%19.7 şeklinde bulunmuştur. $\alpha$-s elüloz miktarı, kayın (Fagus orientalis) odununda \%41.5 (Tank, 1978), kavak (Populus euroamericana) odununda \%42.8 (Akgül ve Kurc1, 2002) ve yalancıakasya (Robinia pseudoacacia) odununda \%51.6 (Kırc1, 1987) olarak saptanmıştır.

Örneklerde tespit edilen holoselüloz, selüloz, $\alpha$-s elüloz, eks traktif madde miktarları odunla karş ılaştırılabilir düzeyde iken, kül, soğuk su çözünürlüğü, sıcak su çözünürlüğü ve $\% 1 \mathrm{NaOH}$ çözünürlügüu değerleri odundan oldukça yüksek seviyelerde bulunmuştur. Lignin miktarları ise daha çok yapraklı odunu değerlerine benzerlik göstermektedir.

Selüloz ve hemiselülozlar hidroliz uygulanmasiyla monosakkarit birimlerini ürün olarak sunmaktadırlar. Monosakkaritler mayalandırma, hidrilleme ve asit uygulanması işlemleri sonucunda farklı ürünlere dönüştürülebilmektedir (Wegener, 1982; Fengel ve Wegener, 1984). Çalışmada, araştırma konusu maki bitkilerinin oduna benzer düzeyde polis akkarit potansiyeline sahip oldukları görülmüştür. Bu özellikleri itibariyle de araştırma türlerinin oduna alternatif hammadde olabilecekleri görülmektedir.

Yapılan bir çalışmaya göre, kağıt üretiminde kullanılabilecek olan lignoselülozik bir materyalin selüloz miktarının $\% 30$ oranından daha yüksek olması gerekmektedir (Tutuş, 2000). Farklı bir çalışmada ise kağıt endüstrisinde kullanilacak hammaddenin $\% 35$ ve üstü selüloz, \%40 ve üstü $\alpha$-s elülozoranına sahip olmasının kağit hamuru üretimi açısından uygun olduğu belirtilmiştir (Çömlekçioğlu, 2005). Çalışmamızda saptanan selülozve $\alpha$ selüloz değerleri, çalışılan türlerin kağıt hamuru üretimine hammadde olabilecek niteliğe sahip olduklarını göstermektedir.
Lignin, kağıt üretim prosesinde ağartılmamış hammadde de lif maddesi bileşeni, ağartma ve şekerleştirme işlemlerinden sonra ise enerji hammaddesi ve polimer hammadde olarak önem taşımakta ayrıca çeşitli dönüşüm ürünlerini sunmaktadır (Wegener, 1982; Fengel ve Wegener, 1984). Çalışmada tespit edilen lignin miktarları, söz konusu bitkilerin bu doğrultuda oduna alternatif olabileceklerini ortaya koymaktadır.

Selüloz türevleri endüstrisinde kullanılacak hamurlarda ( $\alpha$ hamuru) kül bulunması tercih edilmeyen bir durumdur. Hammaddede bulunan kül miktarı ve külü oluşturan bileşiklerin odunun $\mathrm{pH}$ derecesini etkilediği bilinenen bir gerçektir. (Kırcı, 2009). Bu doğrultuda bakıldığında çalışmaya konu olan bitkilerin kül oranı, hammadde olarak kullanılabilme yönünden iğne yapraklı ve yapraklı türlere göre olumsuz sonuç sunmaktadır.

Odundaki ekstraktif maddelerin tamamını tek bir çözücüde izole etmek mümkün olmamaktadır. Genellikle etanol-benzen, etanol-toluen ve etanol-siklohekzan karışımları kullanılarak odundaki bileşenlerden daha çok yağlar, reçine, stereoller ve terpenlerden farklı olarak suda çözünebilen organik maddeler de çözülebilmektedir (Garves, 1981). Sicak su ekstraksiyonuyla ise inorganik tuzlar ve düşük moleküllü polisakkaritlerin yanı sıra bir miktar reçine ve nişasta da çözünmektedir. Sudan, bazı türlerde hemiselülozlar için de çözücü olarak faydalanılmaktadır. \%1 NaOH ekstrakisyonu ile odundaki bir kısım lignin, düşük moleküllü hemiselülozlar ve bir kısım düşük moleküllü selüloz çözünebilmektedir (Pettersen, 1984). Çalışmadaki türler kağıt hamuru üretimine uygun olmakla beraber çözünürlük değerlerinin özellikle de \%1 NaOH çözünürlügünün yüks ek olmas 1 kağıt hamuru üretiminin verimini azaltacaktır (Fengel ve Wegener, 1984). $\mathrm{Bu}$ nedenle araştırma türlerinin selüloz türevleri üretiminde hammadde olarak kullanılmalarının daha verimli olacağ 1 söylenebilir.

HPLC analizleri sonucunda elde edilen ve fenolik ekstraktiflerin tespitinde kullanılan standartlara ait kromatogram Şekil 1'de, tespih, çılbırtı, mersin, karaçalı ve menengiç örneklerine ait kromatogramlar Şekil 2, 3, 4, 5 ve 6'da gösterilmiştir. 


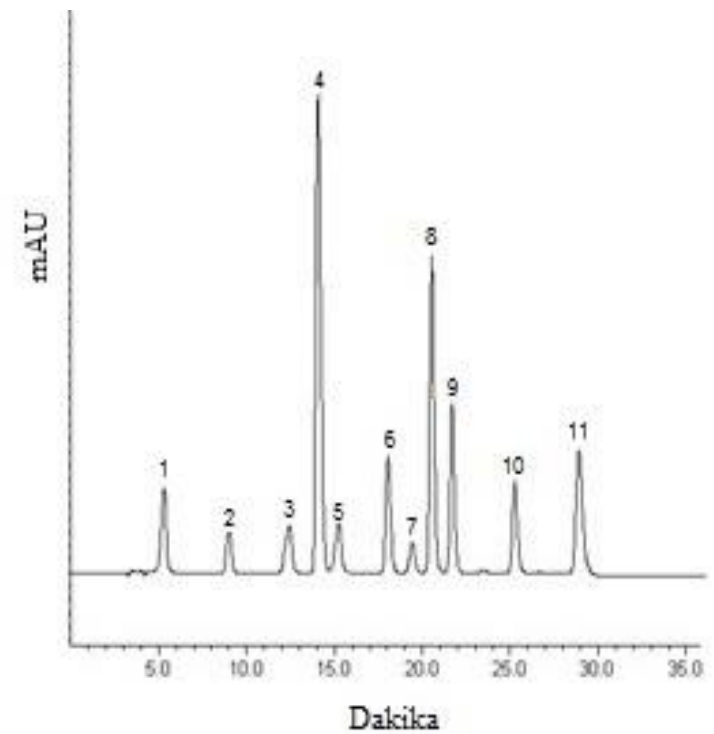

Şekil 1. Standartlara ait HPLC kromatogramı (1:gallik asit, 2:protokateşik asit, 3:kateşin, 4:p-hidroksibenzoik asit, 5:klorojenik asit, 6:kafeik asit, 7:epikateşin, 8:siringik asit, 9:vanilin, 10:p-kumarik asit, 11:ferulik asit)

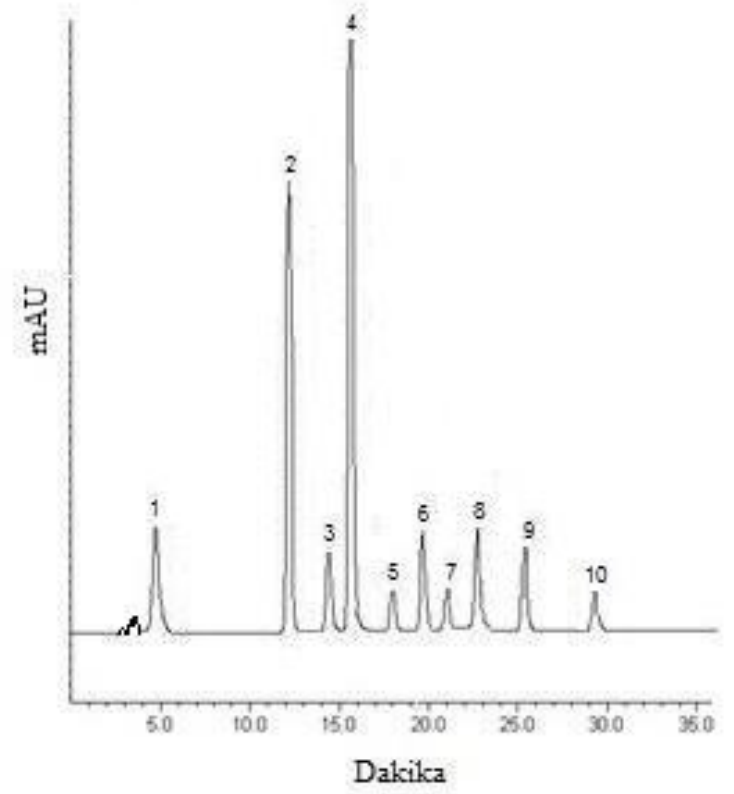

Şekil 2. Tespih örneğine ait HPLC kromatogramı (1:gallik asit, 2:kateşin, 3:p-hidroksibenzoik as it, 4:klorojenik asit, 5:kafeik asit, 6:epikateşin, 7:siringik asit, 8:vanilin, 9:pkumarik asit, 10:ferulik asit)

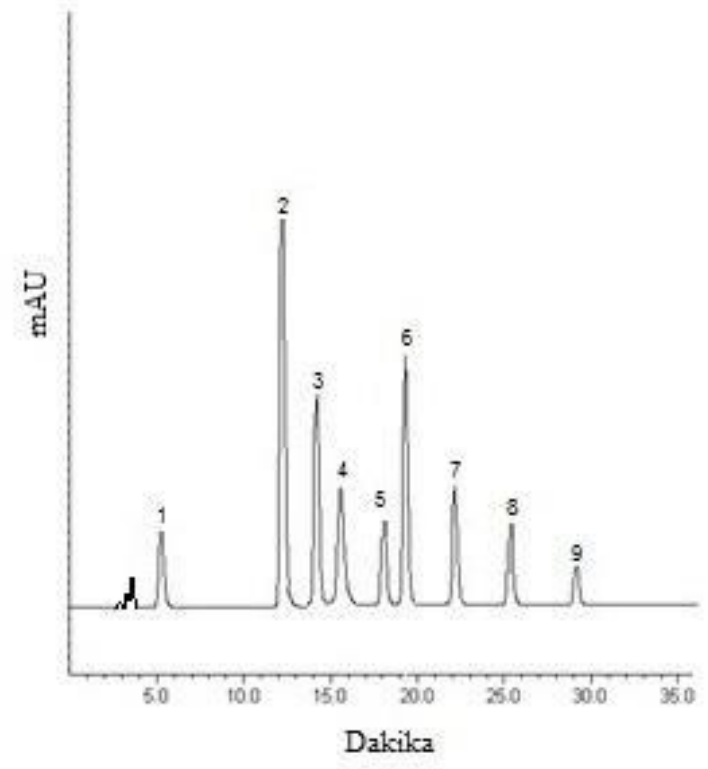

Şekil 3. Çılbırtı örneğine ait HPLC kromatogramı (1:gallik asit, 2:kateşin, 3:p-hidroksibenzoik asit, 4:klorojenik asit, 5:kafeik asit, 6:epikateşin, 7:vanilin, 8:p-kumarik asit, 9:ferulik asit)

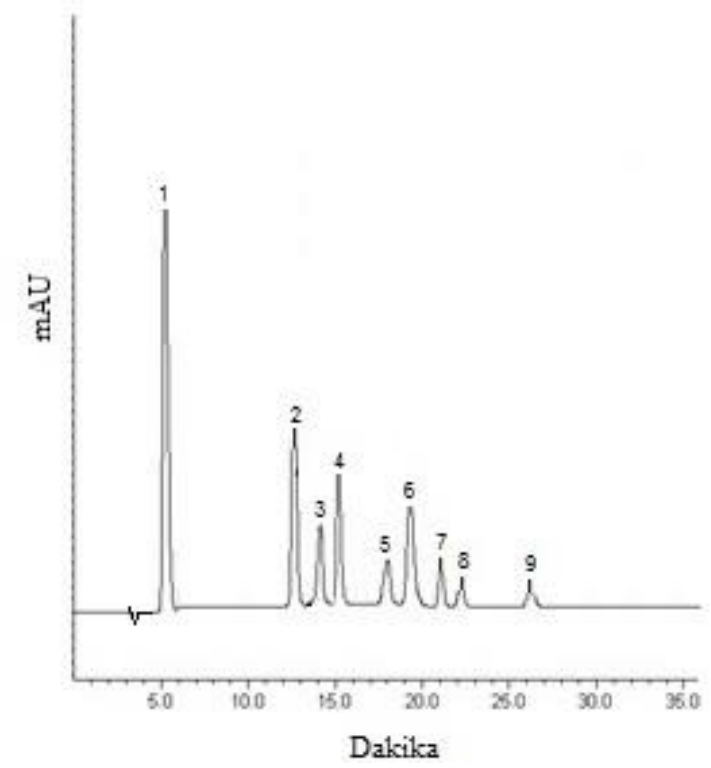

Şekil 4. Mersin örneğine ait HPLC kromatogramı (1:gallik asit, 2:kateşin, 3:p-hidroksibenzoik asit, 4:klorojenik asit, 5:kafeik asit, 6:epikateşin, 7:siringik asit, 8:vanilin, 9:pkumarik asit) 


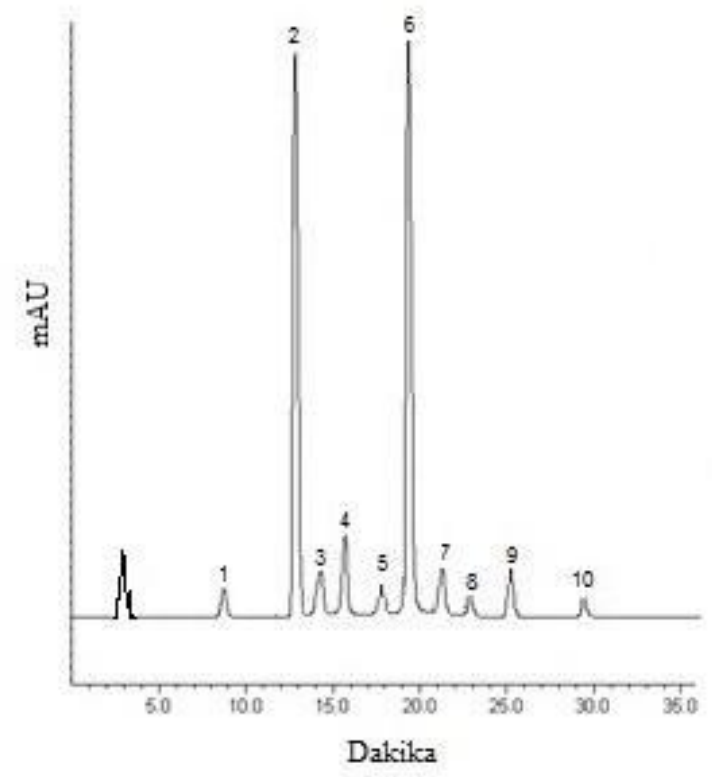

Şekil 5. Karaçalı örneğine ait HPLC kromatogramı (1:protokateşik asit, 2:kateşin, 3:p-hidroksibenzoik asit, 4:klorojenik asit, 5:kafeik asit, 6:epikateşin, 7:siringik asit, 8:vanilin, 9:p-kumarik asit, 10: ferulik asit)

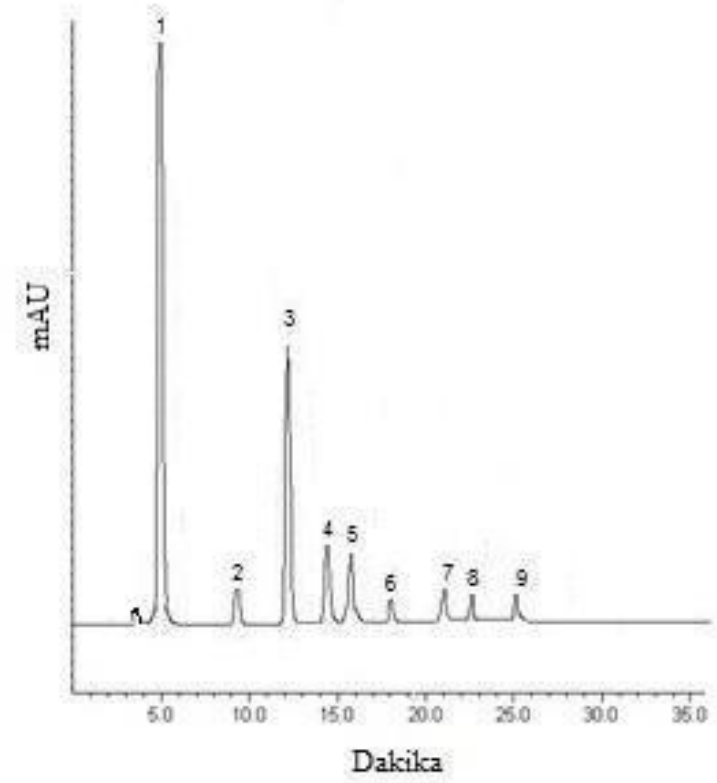

Şekil 6. Menengiç örneğine ait HPLC kromatogramı (1:gallik asit, 2:protokateşik asit, 3:kateşin, 4:phidroksibenzoik asit, 5:klorojenik asit, 6:kafeik asit, 7:siringik asit, 8:vanilin, 9:p-kumarik asit)

Tespih, çılbırtı, mersin, karaçalı ve menengiçte miktar bakımından en baskın fenolik ekstraktif madde sirasıyla klorojenik asit $(0.15 \mathrm{mg} / \mathrm{g})$, kateşin $(0.08 \mathrm{mg} / \mathrm{g})$, gallik asit $(0.59 \mathrm{mg} / \mathrm{g})$, epikateşin asit $(0.85 \mathrm{mg} / \mathrm{g})$ ve gallik asit $(0.91$ $\mathrm{mg} / \mathrm{g}$ ) şeklinde elde edilmiştir. Toplam fenolik ekstraktif madde miktarı ise tespihde $0.43 \mathrm{mg} / \mathrm{g}$, çllbırtıda $0.3 \mathrm{mg} / \mathrm{g}$, mersinde $1.39 \mathrm{mg} / \mathrm{g}$, karaçalida $2.01 \mathrm{mg} / \mathrm{g}$ ve menengiçte $1.73 \mathrm{mg} / \mathrm{g}$ olarak belirlenmiştir (Çizelge 3).
Çizelge 3. Örneklerdeki fenolik ekstraktif madde kompozisyonu (mg/g)

\begin{tabular}{lrrrrr}
\hline Fenolik ekstraktif & Tespih & Çlbırt1 & Mersin & \multicolumn{2}{c}{ Karaçalı Menengiç } \\
\hline gallik asit & 0.03 & 0.02 & 0.59 & - & 0.91 \\
protokateşik asit & - & - & - & 0.03 & 0.07 \\
kateşin & 0.12 & 0.08 & 0.25 & 0.84 & 0.36 \\
$p$-hidroksibenzoik asit & 0.02 & 0.04 & 0.1 & 0.05 & 0.14 \\
klorojenik asit & 0.15 & 0.03 & 0.17 & 0.09 & 0.13 \\
kafeik asit & 0.01 & 0.02 & 0.04 & 0.02 & 0.02 \\
epikateşin & 0.03 & 0.05 & 0.15 & 0.85 & - \\
siringik asit & 0.01 & - & 0.05 & 0.05 & 0.05 \\
vanilin & 0.03 & 0.03 & 0.02 & 0.01 & 0.02 \\
$p$-kumarik asit & 0.02 & 0.02 & 0.02 & 0.06 & 0.03 \\
ferulik asit & 0.01 & 0.01 & - & 0.01 & - \\
Toplam & 0.43 & 0.30 & 1.39 & 2.01 & 1.73 \\
\hline
\end{tabular}

Kılıç ve Niemz (2012) tarafindan tropik türlere ait odunlardaki toplam fenolik ekstraktif madde miktarları Ramin'de 1.17 mg/g, Danta'da $2.81 \mathrm{mg} / \mathrm{g}$, Afzelia'da 13.92 $\mathrm{mg} / \mathrm{g}$, Gaboon'da $4.72 \mathrm{mg} / \mathrm{g}$, Canalate'de $0.36 \mathrm{mg} / \mathrm{g}$, Wenge'de $0.32 \mathrm{mg} / \mathrm{g}$, White Lauan'da $0.55 \mathrm{mg} / \mathrm{g}$, Opepe'de $0.26 \mathrm{mg} / \mathrm{g}$, Bongossi'de $0.98 \mathrm{mg} / \mathrm{g}$, Merbau'da $1.64 \mathrm{mg} / \mathrm{g}$, Mansonia'da $0.87 \mathrm{mg} / \mathrm{g}$ ve Zebrano'da $0.85 \mathrm{mg} / \mathrm{g}$ olarak belirlenmiştir.

Kılıç vd. (2011) bazı iğne yapraklı türlerinin kozalak ve meyvelerindeki toplam fenolik eks traktif madde miktarlarını Abies equi-trojani'de $0.68 \mathrm{mg} / \mathrm{g}$, Abies cilicica'da 0.98 $\mathrm{mg} / \mathrm{g}$, Abies nordmanniana'da $1.13 \mathrm{mg} / \mathrm{g}$, Abies bornmülleriana'da $3.69 \mathrm{mg} / \mathrm{g}$, Pinus halepensis'te 1.17 $\mathrm{mg} / \mathrm{g}$, Pinus pinea'da $0.29 \mathrm{mg} / \mathrm{g}$, Pinus sylvestris'te 0.06 $\mathrm{mg} / \mathrm{g}$, Pinus nigra'da $0.46 \mathrm{mg} / \mathrm{g}$, Pinus brutia'da $0.38 \mathrm{mg} / \mathrm{g}$, Picea orientalis'te $0.54 \mathrm{mg} / \mathrm{g}$, Cupressus smp. var. horizantalis'te $3.31 \mathrm{mg} / \mathrm{g}$, Cupressus smp. var. piramidalis'te $6.39 \mathrm{mg} / \mathrm{g}$, Juniperus excelsa'da $0.20 \mathrm{mg} / \mathrm{g}$ ve Juniperus phoenicea'da $0.60 \mathrm{mg} / \mathrm{g}$ şeklinde tespit etmişlerdir.

Wilför vd. (2009) bazı iğne yapraklı türlerinin kabuklarındaki toplam fenolik ekstraktif madde miktarlarını Abies pindrow'da 39.06 mg/g, Pinus wallichiana'da 34.09 $\mathrm{mg} / \mathrm{g}$, Pinus roxburghii'de $39.30 \mathrm{mg} / \mathrm{g}$, Pinus gerardiana'da $23.00 \mathrm{mg} / \mathrm{g}$, Taxus fuana'da $58.26 \mathrm{mg} / \mathrm{g}$ ve Cedrus deodara'da $26.52 \mathrm{mg} / \mathrm{g}$ olarak saptanmıslardır.

Çalışmadaki maki türlerinde tespit edilen toplam fenolik ekstraktif madde miktarları kabukta (Wilför vd., 2009) belirlenen değerlerden oldukça düşük düzeylerde iken, odun (Kılıç ve Niemz, 2012), kozalak ve meyvelerde (Kılıç vd., 2011) saptanan değerlerle karşılaştırilabilir seviyelerdedir.

Gida maddesi olarak sıkça kullanılan bazı sebze ve meyvelere ait toplam fenolik madde miktarları patateste $0.234 \mathrm{mg} / \mathrm{g}$ (Bushway vd., 1983), elmada $0.343 \mathrm{mg} / \mathrm{g}$, armutta $0.15 \mathrm{mg} / \mathrm{g}$ (Spanos ve Wrolstad, 1992), üzümde $0.0435 \mathrm{mg} / \mathrm{g}$ ve çilekde $0.0516 \mathrm{mg} / \mathrm{g}$ (Hertog, 1993), şeftalide $0.336 \mathrm{mg} / \mathrm{g}$ (Köksal, 2008), böğürtlende $3.30 \mathrm{mg} / \mathrm{g}$ ve ahudududa $0.69 \mathrm{mg} / \mathrm{g}$ (Pehluvan ve Güleryüz, 2004), nar posasında $2.15 \mathrm{mg} / \mathrm{g}$ (Pande ve Akoh, 2009) şeklinde rapor edilmiştir. Çalışma konusu türlere ait değerler, bu değerlerle karşılaştırıldığında söz konusu maki türlerinin önemli düzeylerde fenolik madde miktarlarına sahip oldukları anlaşılmaktadır. 


\section{Sonuç}

Çalışmada maki bitkileri olan tespih, çılbırtı, mersin, karaçalı ve menengiçte kimyasal içerik ve fenolik ekstraktifler incelenmiştir. Holoselüloz, selüloz, $\alpha$-selüloz ve lignin miktarları bakımından söz konusu bitkiler odun hammaddesinin kullanılabildiği kimyasal proseslerde faydalanabilecek özellikler göstermektedirler. Ancak bitkilerdeki kül miktarları oduna oranla yüksek değerler sunmakta olup, bu bakımdan bir kısım prosesler için hammadde olabilme yönünde olumsuzluk sergilemektedirler. Çözünürlük değerleri odunla karşılaştırıldığında, çalışma materyali bitkilerin orman ürünleri endüstrisine ait ilgili proseslerde kullanılabileceklerine işaret etmektedir. Maki türlerinden elde edilen fenolik madde çeşitliliğine ve miktarlarına bakıldığında, söz konusu bitkilerin sentezlenerek ticari antioksidan üretiminde kullanilabileceklerini ortaya koymaktadir.

\section{Kaynaklar}

Akgül, M., Kırc1, H., 2002. Kavak odunundan etanol-su yöntemiyle çözünebilir hamur üretimi olanaklarının araştırılması. KSÜ Fen ve Mühendislik Dergisi, 5(1): 72-85.

Bushway, R.J., Bureau, J.L., McGann, D.F., 1983. Alphachaconine and alpha-solanine content of potato peels and potato peel products. J. Food Science, 48: 84-86.

Caponio, F., Alloggio, V., Gomes, T., 1999. Phenolic compounds of virgin olive oil: influence of pastepreperationtechniques. Foodchemistry, 64: 203209.

Cooper, P., Balantinecz, J., 1999. Agricultural waste materials for composites: A Canadian reality. Centre for Management Technology Global Panel Based Conference, Nikko Hotel, Kuala Lumpur, 18-19 October.

Çömlekçioğlu, N., 2005. Ülkemizde doğal olarak yayılış gösteren Crambe Spp.'nin kimyasal içeriğinin ve endüstriyel kullanım alanlarının incelenmesi. Yüksek Lisans Tezi, K.S.Ü., Kahramanmaraş.

Dönmez, İ.E., Hemming, J., Willför, S., 2016. Bark extractives and suberin monomers from Arbutus andrachne and Platanus orientalis. BioRes., 11(1): 2809-2819.

Faydaoğlu, E., Sürücüoğlu, M., 2013. Tıbbi ve aromatik bitkilerin antimikrobiyal, antioksidan aktiviteleri ve kullanım olanakları. EÜFBED-Fen Bilimleri Enstitüsü Dergisi, 6(2): 233-265.

Fengel, D., Wegener, G., 1984. Wood Chemistry, Ultrastructure, Reactions. Walter de Gruyter Verlag, Berlin, New York.

Garves, K., 1981. Zum ersatz von benzol in holzextraktionen. Holz als Roh-und Werkstoff, 39: 253254.

Gülsoy, S.K., 2003. Bazı yapraklı ağaçların kanserli ve normal odunlarının kimyasal-anatomik yapıları, lif morfolojisi ve kağıt özellikleri yönünden araştırılması. Yüksek Lisans Tezi, Z.K.Ü., Bartın.
Hertog, M.G.L., 1993. Content of potentially anticarcinogenic flavonoids of 28 vegetables and 9 fruits commonly consumed in the Netherlands. J. Agric. Food Chem., 40: 2379-2383.

Kılıç, A., Sarıusta, S. E., Hafizoğlu, H., 2010. Sarıçam, Karaçam ve Kızılçam bas inç odununun kimyas al yapısı. Bartın Orman Fakültesi Dergisi, 12(18): 33-39.

Kılıç, A., Hafizoğlu, H., Tümen, İ., Dönmez, İ. E., Sivrikaya, H., Hemming, J., 2011. Phenolic extractives of cones and berries from Turkish coniferous species. Eur. J. Wood Prod., 69: 63-66.

Kılıç, A., Niemz, P., 2012. Extractives in some tropical woods. Eur. J. Wood Prod., 70:79-83.

Kırc1, H., 1987.Yalanc1 Akasya (Robinia pseudoacacia L.) odununun kağıt endüstrisinde değerlendirilme olanakları, Yüksek Lisans Tezi, K.T.Ü., Trabzon.

Kırc1, H. 1991. Alkali sülfit antrakinon etanol (ASAE) yöntemiyle kızılçam (Pinus brutia Ten.) odunundan kağıt hamuru üretim koşullarının belirlenmesi. Doktora Tezi, K.T.Ü., Trabzon.

Kırcı, H., Ateş, S., Boran S., 2002. Anadolu karaçamı (Pinus nigra subsp. Pallasiana) odunlarının as li hücre çeperi bileşenlerinin belirlenmesi ve kağıt hamuru üretimine uygunluğunun araştırılması. II. Ulusal Karadeniz Ormancılık Kongresi, 3: 1057-1063.

Kurc1, H., 2009. Kağıt Hamuru Endüstrisi. Ders Notları Serisi, Geliştirilmiş 4. Baskı, K.T.Ü., Orman Fakültesi, Trabzon.

Köksal, G., 2008. Şeftali meyvesinde fenolik made dağılımı ve pulpa işlemi sırasında değişimi. Doktora Tezi, A.Ü., Ankara.

Kurschner, K., Hoffer, A., 1969. Ein neues verfahren zur bestimmung der zellulose in hölzern und zellstoffen. Technologie und Chemie der Papier- u. ZellstoffFabrikation, 26: 125-139.

Öner, N., Aslan, S., 2002. Titrek kavak odununun teknoloji özellikleri ve kullanım yerleri. SDÜ Orman Fakültesi Dergisi, 1: 135-146.

Pande, G., Akoh, C.C., 2009. Antioxidant capacity and lipid characterization of six georgia-grown pomegranate cultivars. J. Agric. Food Chem., 57(20): 9427-9436.

Pehluvan, M., Güleryüz. M., 2004. Ahududu ve böğürtlenlerin insan sağlığı açısından önemi. Bahçe, 33(1-2): 51-57.

Pettersen, R.C., 1984. The chemical composition of wood. In: Rowel, R.M. (Ed.), The Chemistry of Solid Wood. Advances in Chemistry Series No: 207, Chapter: 2, 57 $126 \mathrm{pp}$, Washington.

Spanos, G.A., Wrolstad, R.E., 1992. Phenolics of apple, pear and white grape juices and their changes with processing and storage-A review. J. Agric. Food Chem. 40: $1478-1487$.

Tank, T., 1978. Türkiye kayın ve gürgen türlerinin NSSC (Nötral Sülfit Yarkimyasal) metodu ile değerlendirilmesi. İ.Ü. Orman Fakültesi Yayınlan No: 2326/231, İstanbul.

Tutuş, A., 2000. Buğday (Triticumaestivum L.) saplarından kağıt hamuru üretiminde kullanılan soda-oksijen, sodaantrakinon ve soda yöntemlerinin silis problemi ve diğer yönlerden karşılaştırılmas ı. Doktora tezi, Z.K.Ü., Bartın.

Usta, M., 1989. Sülfat pişirmesinde açığa çıkan toplam indirgenmiş kükürt (TRS) bileşiklerinin oksijenle yükseltgenmesi. Doktora Tezi, K.T.Ü., Trabzon. 
Wegener, G., 1982. Die Rolle des Holzes als Chemierohstoff und Energieträger, Teil 2: Verwertungsmöglichkeiten für Cellulose, Polyos en und Lignin. Holz als Roh- und Werkstoff, 40: 209-214.

Willför, S.M., Hemming, J., Reunanen, M., Holmbom, B., 2003. Phenolic and lipophilic extractives in scots pine knots and stemwood. Holzforschung, 57: 359-372.
Willför, S., Ali, M., Karonen, M., Reunanen, M., Arfan, M., Harlamow, R., 2009. Extractives in bark of different conifer species growing in Pakistan. Holzforschung, 63: 551-558.

Wise, E.L., Karl, H.L., 1962. Cellulose and Hemicellulose in Pulp and Paper Science and Technology, Vol. 1: Pulp. Libby, C.E. (Ed.), Mc Graw Hill Book Co., New York. 